\title{
A criação do IADÊ, Instituto de Arte e Decoração - 1959
}

Auresnede Pires Stephan (Eddy) é Bacharel em Desenho Industrial pela Faculdade de Artes Plásticas daFundação Armando Álvares Penteado em 1970. Mestre em Educação, Arte e História da Cultura pela Universidade Presbiteriana Mackenzie em 2007. Especialização nas modalidades Design Gráfico, Design e Humanidade pela Universidade de São Paulo, no Centro Universitário Maria Antônia, em 2011. Doutor em Ciências/ Design pela Faculdade de Arquitetura e Urbanismo da Universidade de São Paulo em 2019. Professor universitário no curso de Moda da Faculdade Santa Marcelina e no curso de Design da Escola Superior de Propaganda e Marketing de São Paulo. Consultor na área de Design <apsdesign@uol.com.br > ORCID: 0000-0003-4995-5185
Resumo O IADÊ foi uma escola fundada, em 1959, por iniciativa do cenógrafo e professor italiano de história da Arte Ítalo Bianchi e pelo decorador e professor português Álvaro Landerset. O conceito básico da instituição era a criação de novos paradigmas na estrutura de ensino, com seu programa curricular de vanguarda que abrangia as áreas de design, arquitetura e artes visuais. Naquele período, o pré-requisito para ingressar no Curso de Decoração, com duração de dois anos, era o diploma ginasial. Seu currículo era constituído de aulas teóricas, que cultivavam a capacidade de julgamento estético e estimulavam a criatividade, e de aulas práticas, que ensinavam as habilidades próprias do setor, oferecendo experiências de criação que se somavam às aulas técnicas e fornecendo os elementos concretos para a realização de trabalhos em nível profissional.

Palavras chave Ensino, Curso, Decoração, Metodologia, Pioneirismo. 


\section{The foundation of IADÊ, Institute of Art and Decoration- 1959}

Abstract IADÊ was a school founded in 1959 by the association of an Italian teacher of History of Art, named Ítalo Bianchi, and by a Portuguese teacher named Álvaro Landerset. The main concept of the institution was to build a new paradigm in the education system. Its forefront school curriculum encompassed areas such as design, architecture and visual arts. At that time, the requirement to be admitted at the two years long Decor course was the middle school degree. Its curriculum was built on theoretical classes to develop the ability of aesthetical judgment and to stimulate creativity. The practical classes developed the abilities specific for each area offering creativity experiences that supported the technical classes, providing solid elements to perform the work in a professional level.

Keywords Teaching, Course, Decor, Methodology, Pioneering.

\section{La creación del IADÊ, Instituto de Arte y Decoración - 1959}

Resumen La IADÊ fue una escuela fundada en 1959 por iniciativa del escenógrafo y profesor italiano de historia del Arte Ítalo Bianchi y el decorador y profesor portugués Álvaro Landerset. El concepto básico de la institución fue la creación de nuevos paradigmas en la estructura de la enseñanza, con un plan de estudios de vanguardia que cubría las áreas de design, arquitectura y artes visuales. En ese momento, el requisito previo para el ingreso al Curso de Decoración, que duraba dos años, era el diploma de secundaria. Su plan de estudios consistía en clases teóricas, que cultivaban la capacidad de juicio estético y estimulaban la creatividad, y clases prácticas, que enseñaban las habilidades especificas del sector, ofreciendo experiencias creativas además de clases técnicas, y proporcionando elementos concretos para realizar trabajos a nivel profesional.

Palabras clave Docencia, Curso, Decoración, Metodología, Pioneros. 


\section{Perfil de Ítalo Bianchi}

A partir de documento enviado pelo seu filho Guido

Bianchi e de sua neta Adriana Bianchi.

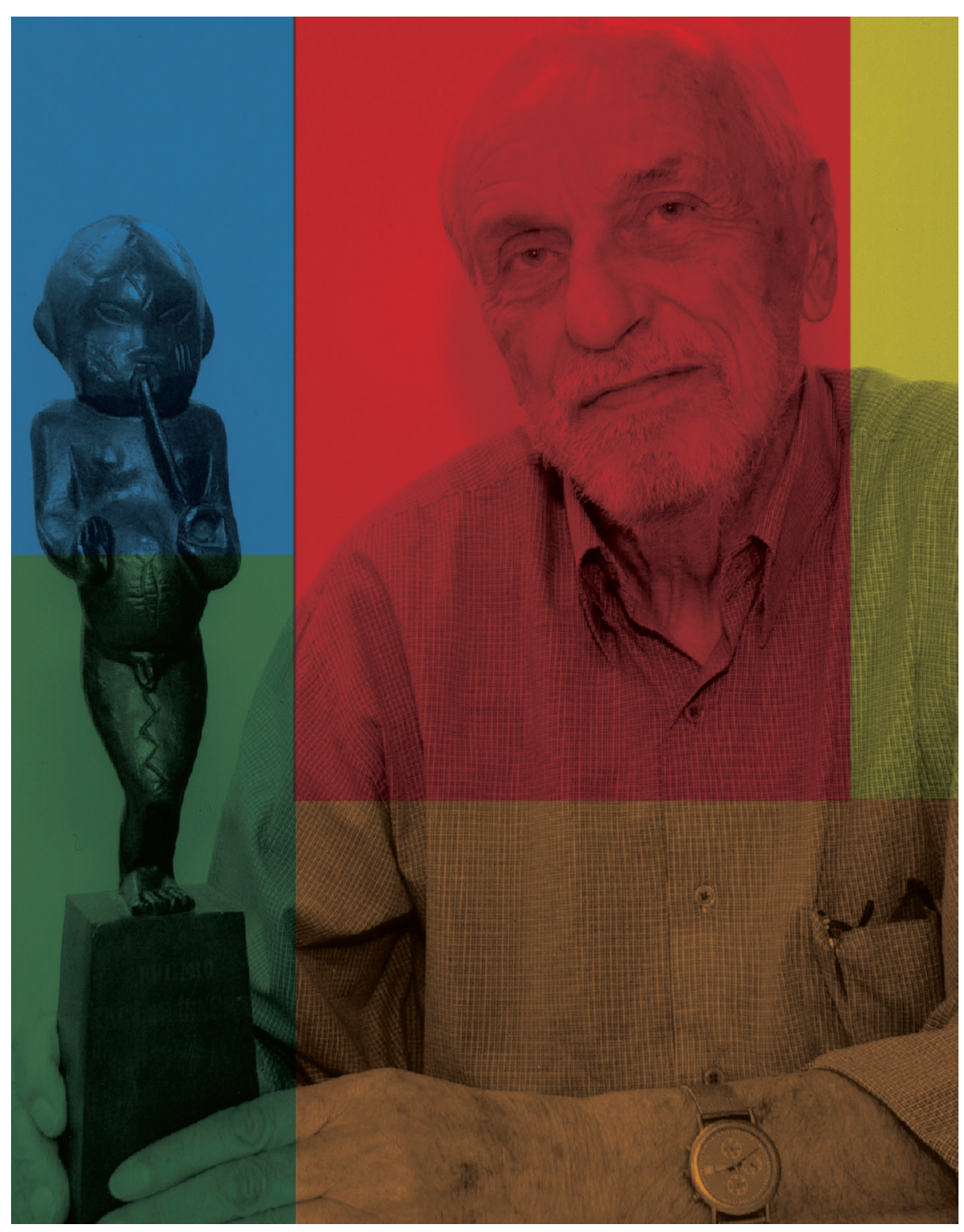

Ítalo Bianchi estudou na Escola de Belas Artes de Milão. No entanto desconheço se ele chegou a ser laureado. Eram tempos muito difíceis e sombrios com o fascismo no poder na Itália. O pai dele, Guido também, foi um artista plástico - escultor e desenhista figurativo - de qualidade e sua mãe, Giuseppina Giovenco, professora de música e cantora lírica formada no Alla Scalla di Milano. Ela sim, laureada com certeza. A família, no entanto, tinha posições políticas antagônicas ao governo ditatorial e fazia oposição aberta. 
O resultado foi uma perseguição implacável que se refletiu na vida social, cultural e profissional de todos. $O$ casal teve dois filhos sendo que a irmã mais velha faleceu de tifo ainda na infância restando apenas o Ítalo.

Guido, o pai, e o filho Ítalo, ambos com formação humanista sólida, se vincularam ao movimento de resistência e no Partido Socialista. O Ítalo foi convocado para servir na marinha em função da $2^{\mathrm{a}}$ Guerra Mundial e desertou. Viveu na clandestinidade e na resistência até a queda de Mussolini. Nunca comentei sobre isso com ele, mas imagino que o vínculo formal com a Escola de Belas Artes se perdeu com o processo político que virou a vida das pessoas de ponta cabeça. Mas o estudo teórico e abrangente ficou e ele sempre se referia e depositada à sua formação acadêmica a razão de sua capacidade artística multimídia.

Ítalo Bianchi chegou ao Brasil em 1950 e ficou um ano na Argentina por conta de um contrato de trabalho. Lá deu de cara com o governo de Perón e tratou de terminar o serviço e retornar ao Brasil. De volta, foi morar no Bixiga, em São Paulo, e passou a se encontrar com os imigrantes da época em sua maioria intelectuais e artistas. A sequência foi mais ou menos assim:

- Faz contratos avulsos com Ciccilo Matarazzo desenhando stands, etc. (recebia pagamentos no caixa da Fábrica Matarazzo);

- Participa das comemorações do IV Centenário de São Paulo projetando stands e material de divulgação;

- Trabalha como assistente e cenógrafo para o TBC Teatro Brasileiro de Comédia;

- Ingressa na equipe da Cia. Cinematográfica Vera Cruz e ganha o prêmio Saci de Cinema de melhor cenografia com o filme "Uma pulga na balança".

Durante oito anos coordena a edição do Suplemento Literário do jornal o Estado de São Paulo, importante semanário, e assina o design gráfico da publicação. Fundador do IADÊ, coordena o conteúdo curricular e realiza diversos projetos de arquitetura de interiores, desenvolvendo mobiliário, tapeçaria, do setor de projetos da escola. Desenvolve embalagens, identidade e programação visual. Muda-se para o Nordeste do Brasil em dezembro de 1967 e é contratado pela maior agência de publicidade do Recife: a Proene. Desliga-se e abre um estúdio de criação e projetos de comunicação passando a trabalhar para vasta clientela da região. Funda a agência de propaganda e comunicação Ítalo Bianchi Publicitários Associados, uma segunda "escola" após o IADÊ. Ganha diversos prêmios e inaugura um novo ciclo de comunicação e propaganda regional. Inicia a atividade de consultor de comunicação em escritório próprio. Passa a lecionar comunicação e cinema da UNINASSAU. Escreve crônicas e ensaios para o Jornal do Commercio de Pernambuco e lança dois livros com esses textos. 
O Ítalo ainda está na memória das pessoas que o conheceram e que conviveram com ele. Um homem de fino trato, profundo conhecedor de história da arte, que fazia de tudo para repassar o seu conhecimento acumulado para os que conviviam com ele. Tinha prazer em trabalhar e ensinar. Formou dezenas de profissionais. Sabia descobrir talentos e incentivava o crescimento intelectual das pessoas.

\section{Perfil de Paulo Ramos Machado}

Professor e conferencista nas áreas de História da arte e da música.

Fig 2. Paulo Ramos Machado

Fonte Acervo da Sra. Regina Stela Barcelos Machado

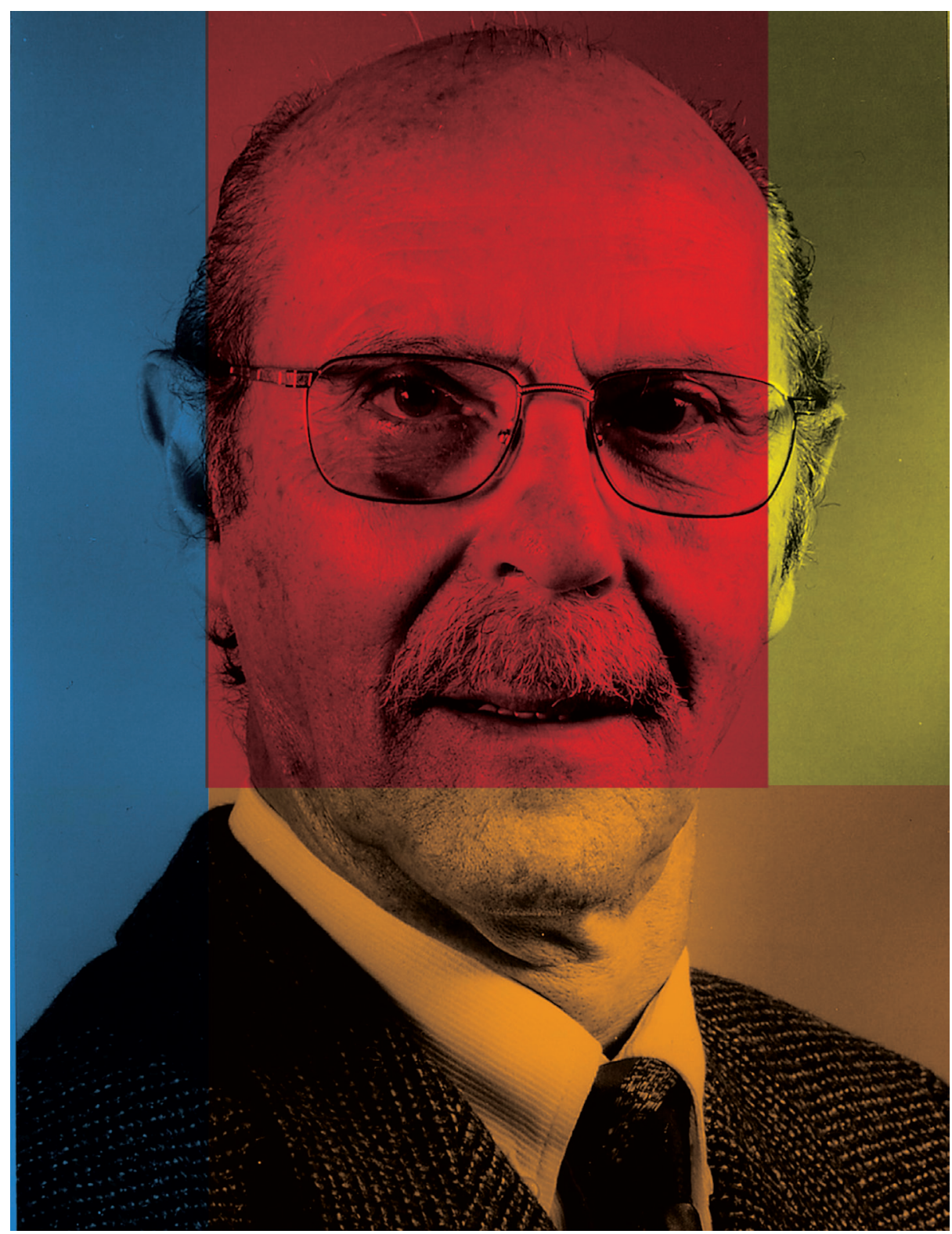


Criador, redator e coordenador de realização de obras didáticas em audiovisuais e CD-ROM, sobre diversos movimentos estéticos tais como Impressionismo, Expressionismo, Surrealismo, Barroco, Barroco Mineiro, etc.

Graduação em Música (Piano) pelo Conservatório Dramático e Musical de São Paulo. Professor normalista. Cursos de Arte e de Língua Francesa, realizados em Paris durante estadia de um ano naquela capital. Cofundador do IADÊ - Instituto de Arte e Decoração - SP. Cofundador da Escola Municipal de Música, SP, do qual foi diretor durante a administração de Faria Lima. Coautor dos projetos de instituição no sistema de ensino do Estado de São Paulo, dos cursos Técnico de Desenho de Comunicação, de Música e de Administração de Empresas, todos em grau médio e atualmente em funcionamento. Escreveu e produziu vários programas de arte na TV Cultura.

Em Paris trabalhou durante um ano na Rádio Difusão Francesa, traduzindo e narrando programas culturais para o Brasil. Ex-Conselheiro do Conselho Estadual de Educação na Câmara do Ensino Médio. Ex-Chefe de Gabinete da Secretaria de Turismo Municipal, durante a administração Figueiredo Ferraz. Ex-Professor Auxiliar de Ensino de História da Arte na Escola de Comunicações e Artes da Universidade de São Paulo (ECA). Em 1997 foi admitido como membro da ABCA - Associação Brasileira de Críticos de Arte. Em 1992, a partir de fevereiro, exerceu atividades docentes nas Faculdades Santa Marcelina, Marcelo Tupinambá e Carlos Gomes.

Realizou uma série de audiovisuais didáticos abordando vários períodos da História da Arte, como Pré-História, Grécia, Idade Média, Renascimento, Barroco, Impressionismo, etc.

\section{A criação do IADÊ}

O IADÊ foi uma escola fundada em 1959 pelo italiano, cenógrafo e professor de história da arte Ítalo Bianchi e pelo professor e decorador Álvaro Landerset Simões, de nacionalidade portuguesa.

Vindos daEuropa, Ítalo BianchieÁlvaroLandersetSimões tinham visão do que poderia ser o futuro do desenhoindustrial em São Paulo, cidade que consideravam degrande potencial industriale onde não existia nenhuma escola de nível médio ou de nível superior na área. E, pior, pouco se discutia sobre o assunto.

Ítalo Bianchi, um estrangeiro como tantos outros que aqui chegaram e contribuíram no âmbito da cenografia, publicidade, decoração, e também como um dos pioneiros do assim denominado na época desenho industrial. Seu objetivo inicial era atuar em Recife. No entanto, em 1949, acabou permanecendo em São Paulo devido aos contatos estabelecidos junto à Companhia Cinematográfica Vera Cruz. Foi exercer a função de cenógrafo nesta empresa de maior importância do setor no Brasil naquele período. Além de atuar como cenógrafo, decorador, foi publicitário e secretário do Suplemento Literário do jornal O Estado de São Paulo, referência da intelectualidade paulistana. Após os dez anos de atuação no cenário artístico, tomou uma nova direção fundando o IADÊ com a intenção de firmar o decorador como um profissional respeitado e capaz de desenvolver projetos no âmbito dos espaços interiores. ${ }^{1}$ 
Álvaro Landerset Simões, do IADÊ, veio de Portugal e aqui atuou no campo da decoração. Foi, nos anos 1950 e 1960, responsável técnico pelo interior das agências bancárias do Banco Brasileiro de Descontos (Bradesco).

A narrativa a seguir é baseada na conversa que aconteceu na residência do professor Paulo Ramos Machado, realizada na manhã do dia 30 de março de 2005 pela ex-aluna do IADÊ Leonora Fink Segreto. Podemos considerar que Paulo Ramos Machado também foi um dos fundadores da escola, onde atuou como secretário e professor, além de contribuir muito para manter a qualidade da instituição em todos os aspectos.

Sua atividade no instituto teve início no final de 1959, atendendo ao chamado dos professores Ítalo Bianchi e Álvaro Landerset Simões. A função dele seria a de secretariar a instituição no edifício da Rua Martinho Prado, 191, que havia sido alugado para a instalação da escola. No ano de 1964, o professor Paulo Ramos Machado substitui o professor Ítalo Bianchi e começa a ministrar aulas de história da arte, além de dar continuidade a sua atuação como secretário do IADÊ.

Permaneceu ministrando aulas até o ano de 1971, quando assumiu o cargo de direção na Secretaria de Turismo da Prefeitura do Município de São Paulo, no governo do engenheiro José Carlos de Figueiredo Ferraz, lá permanecendo até o ano de 1973. Com sua saída, a secretaria da escola foi assumida pela ex-aluna e sócia Maria Isabel de Souza Franco.

Cabe aqui uma observação técnica sobre a localização do IADÊ. Não foi por acaso que teve sua sede localizada na Rua Martinho Prado, 191, mas sim por ser uma transversal próxima da Rua Augusta e da Rua Martins Fontes, que eram, naquela ocasião, o centro da elite e da decoração da metrópole que mais crescia no mundo.

Na visão de Maria Isabel de Souza Franco, até então em São Paulo surgiam, em alguns espaços públicos e privados, cursos de curta duração, criados para dar aos alunos algumas noções de estilos históricos e rudimentos técnicos de decoração, geralmente baseados em conceitos que permeavam o século 19 e princípios clássicos do início do século 20 .

A proposta do IADÊ era diversa, e foi por isso que Maria Isabel de Souza Franco lá ingressou em 1961, quando o curso passou de dois para três anos de duração dentro de uma bem articulada estrutura de ensino, no entender dela. Ítalo Bianchi sentia que muita gente ainda não entendia a decoração como a organização do espaço, como arquitetura de interiores. Ele pensou em uma escola que desse ao aluno não apenas uma formação técnica, mas também um embasamento cultural. Criou o curso nos moldes do que foi a Bauhaus, e o sucesso foi imediato. ${ }^{2}$

A escola pretendia criar novos paradigmas na sociedade, ao integrar o estudo do desenho industrial (design), da arquitetura e das artes à indústria e ao mercado. O IADÊ foi uma instituição de vanguarda no Brasil, e essa vanguarda artística e cultural não estava em consonância na visão do governo militar. Personalidades dos campos da arte e da arquitetura, entre elas Sérgio Ferro e muitos outros atuantes professores do instituto, foram obrigados a sair do país para garantir sua sobrevivência. 
Paralelamente, nesse período conturbado da nossa história que foi a década de 1960 o IADÊ sofreu mudanças e muitos objetivos acabaram não se concretizando. Entre eles estava a intenção dos seus fundadores de criar um curso de nível superior denominado arquitetura de interiores. No entanto, o Ministério da Educação e Cultura não o aprovou, por considerar que seria um curso de nível superior conflitante com os cursos de arquitetura. Essa não aprovação foi um dos fatores da posterior criação do Colégio Técnico de Comunicação e do Curso Técnico de Administração de Empresas no ano de 1969 e da continuidade do Curso Livre de Decoração.

Antes da mudança para o novo endereço, na Avenida Paulista, 2.644, no ano de 1965 ocorreu a saída da sociedade inicial do professor e decorador Álvaro Landerset Simões. Nessa ocasião, o professor Ítalo Bianchi dividiu em cotas a parte referente a Álvaro Landerset Simões entre Emilio Fernandez Cano, Michiro Motoda e Maria Isabel de Souza Franco, que passaram, assim, de ex-alunos e professores a integrantes da sociedade que administraria o IADÊ.

A trajetória de fundador e professor do IADÊ de Ítalo Bianchi vai de 1959 a 1967, quando, no dia 5 de dezembro de 1967, ele se muda para o Recife, em Pernambuco, onde abriu uma agência de publicidade e propaganda. Foi uma das empresas pioneiras no setor e se consagrou como uma das agências mais criativas do nordeste brasileiro.

\section{A identidade visual do IADÊ}

A criação da identidade visual do instituto foi responsabilidade de Ítalo Bianchi, tendo como colaborador o professor Álvaro Landerset Simões, e ocorreu no final de 1958, pouco antes do início das atividades letivas. Com base em documentos do acervo particular de Maria Isabel de Souza Franco, constatamos que essa identidade não sofreu, ao longo de toda a existência de 28 anos do IADÊ, nenhuma reformulação ou rejuvenescimento na estrutura gráfica, como também nas cores institucionais (preto e laranja). Em entrevista concedida por Maria Isabel de Souza Franco, fica evidente que Ítalo Bianchi, ao desenvolver a identidade do instituto, conceituava seu projeto dentro das leis enunciadas pelo arquiteto Max Bill, que estudou na Bauhaus e era expoente da arte concreta, que pressupunham "o alinhamento, o ritmo, a regularidade e a lógica interna de desenvolvimento e construção". Esses conceitos projetuais foram princípios que Ítalo Bianchi disseminava em suas aulas de história da arte, tendo como referência a pedagogia da Bauhaus.

Fig 3. Identidade Visual pela simbologia e lettering

Fonte: Acervo de Auresnede Pires Stephan

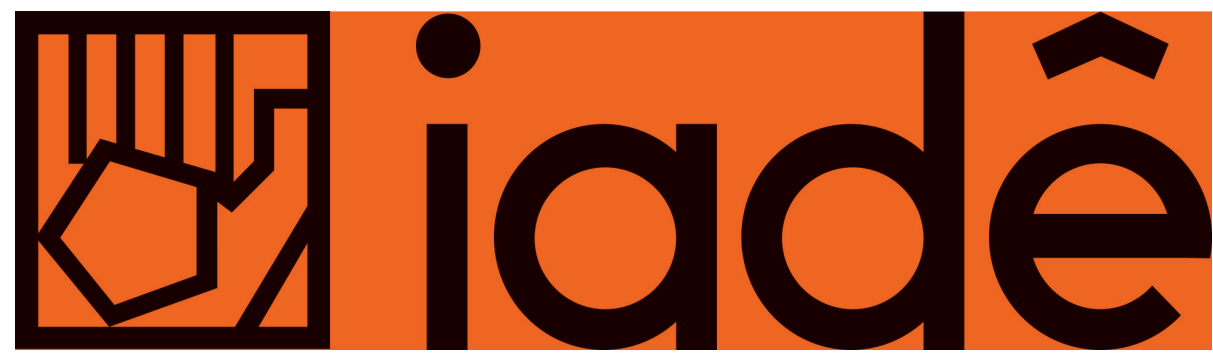

DATJournal v. 5 ก.2 2020 


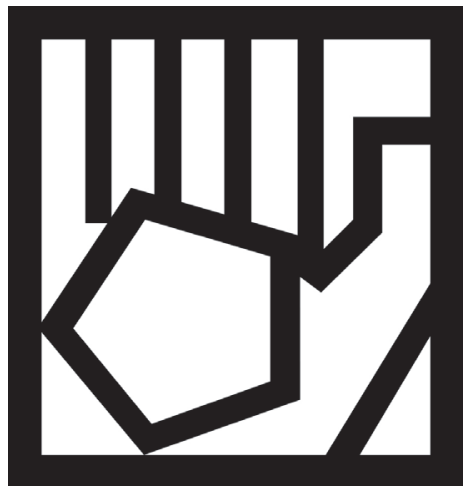

Fig 4. Mão espalmada

Fonte: Acervo de Auresnede Pires Stephan
A identidade é constituída pela simbologia da mão acompanhada do lettering IADÊ a seu lado direito. O conceito estabelecido simbolicamente foi o da geometrização da "mão espalmada do desenhista", com características sintéticas de um pictograma, trazendo a mão inserida dentro de um retângulo definido por linhas espessas.

A palma da mão estilizada é configurada por um pentágono regular. Aqui podemos fundamentar a semântica do conceito simbólico da mão com base em Ronnenberg (2012, p. 380):

Como primeiros instrumentos de criatividade, as mãos do Homo faber imitam a mítica transformação da matéria em um ser distinto por divindades que gravam, esculpem, tecem e forjam a criação. As mãos significam o alcance soberano da criação do mundo consciente; elas personificam a eficácia, diligência, adaptação, invenção, auto expressão e a posse de uma vontade para fins construtivos e destrutivos.

O nome utiliza letras desenhadas, tendo a família tipográfica Futura, ou outras fontes geométricas como inspiração, em caixa baixa. Apesar da semelhança, observamos diferenças entre elas e as letras da fonte Futura, como a proporção do pingo do "i”" e o final do "e". Aqui, na utilização desse tipo de fonte, podemos observar um dos princípios conceituais de Herbert Bayer, gráfico, tipógrafo e professor da Bauhaus, que desenvolveu o princípio de um alfabeto de legibilidade universal. No seu entender, "tal como máquina, arquitetura e cinema moderno, o alfabeto deve também ser uma expressão dos nossos tempos". Bayer, ao criar o alfabeto experimental Sturm Blond, pensou poder superar os limites definidos pelo vaivém das modas. Para tanto, subordinou seu desenho de letra a leis supostamente "atemporais" e "objetivas". A fonte tipográfica, que se caracterizava pela clareza, com evidente construção geométrica, aliava os conceitos de sobriedade, neutralidade, equilíbrio e alta legibilidade. Considerações sintáticas e semânticas semelhantes justificaram o uso de letras sem serifas geométricas por Ítalo Bianchi para a concepção do logotipo do instituto.

\section{Cronologia dos cursos e das sedes do IADÊ}

Conforme informações da aluna, professora e posteriormente diretora do IADÊ Maria Isabel de Souza Franco, vamos aqui apresentar um quadro da trajetória dos cursos ministrados pela escola, suas denominações, localizações e o período em que foram oferecidos.

- Curso de Decoração Duração de dois anos (de 1959 a 1964) Sede na Rua Martinho Prado, 191 (primeira sede)

- Curso de Decoração (Arquitetura de Interiores) Duração de três anos (de 1965 a 1968)

Sede na Av. Paulista, 2.644, do 9a ao $12^{\circ}$ andar (segunda sede) 
- Curso Colegial Técnico de Desenho de Comunicação Duração de três anos (de 1969 a 1987)

- Curso oficial equivalente ao $2^{\circ}$ grau Sede na Av. Paulista, posteriormente na Av. Rebouças 1615, e finalmente na Rua Alves Guimarães 1364, em atividade até o ano de 1987

- Curso de Livre de Decoração Duração de um ano (de 1970 a1987) Foi reeditado com base no antigo curso de três anos

- Curso de Administração de Empresas Duração de três anos (de 1971 a 1978) Curso oficial equivalente ao $2^{\circ}$ grau Sede na Av. Paulista, 2.644, $12^{\circ}$ andar

- Cursos Livres

(de 1959 a 1987)

A intenção original dos fundadores era, desde o início, que o nome do Curso de Decoração fosse Arquitetura de Interiores; no entanto, para efeito de publicidade, a identificação como Curso de Decoração era mais adequada para o grande público. Por outro lado, sempre existiu um questionamento por parte das escolas de nível superior de arquitetura e seus órgãos de classe sobre a efetiva necessidade de uma formação acadêmica específica de decoração específica, uma vez que os cursos de arquitetura já contemplavam essas atribuições, e o embate ocorria também no que diz respeito às atribuições do profissional formado pelo IADÊ.

\section{Conceitos e fundamentos dos cursos no IADÊ}

Fora da grade habitual obrigatória, os alunos tinham a chance de conhecer profissionais do cinema e do teatro, entre tantas expressões artísticas. Por exemplo, Haron Cohen, arquiteto e urbanista, ministrou aulas de história em quadrinhos mostrando a vocação avançada da escola. Editou uma das publicações pioneiras na academia sobre comics, até então marginalizadas.

A interação com a prática não se restringia ao espaço da escola. Fora da grade habitual obrigatória, os alunos tinham a chance de conhecer profissionais do cinema e do teatro, entre tantas expressões artísticas. Por exemplo, Haron Cohen, arquiteto e urbanista, ministrou aulas de história em quadrinhos mostrando a vocação avançada da escola. Editou uma das publicações pioneiras na academia sobre comics, até então marginalizadas. 
A interação com a prática não se restringia ao espaço da escola. Todo o mercado de decoração, que se expandiu na década de 1950, era visitado pelos alunos, que se deslocavam da escola para as lojas e ateliês. Professores e alunos tinham acesso a espaços como Donatelli e Formatex, a fim de participar de aulas sobre tecidos de maneira bem mais concreta do que numa sala de aula. Já os showrooms que despontavam nos anos de $1950 \mathrm{e}$ 1960 - Oca, Hobjeto, Mobília Contemporânea, L'Atelier e Branco \& Preto eram o destino de muitos dos profissionais ao fazerem seus projetos.

O mercado começava a abrir novas frentes e a criar uma dinâmica própria, com escolas, lojas, profissionais e clientes que se conheciam e sabiam onde poderiam encontrar o que precisavam. O IADÊ, nesse período, além da preocupação com o estudante e sua formação, contava com o estúdio profissional, uma inovação que foi um componente de extrema importância para estabelecer alguns dos critérios para a profissão de designer de interiores em São Paulo. Em paralelo a isso, o IADÊ estabeleceu sociedade com uma excelente marcenaria da época, a Pentágono, comandada por Pablo Brioñes, perito na produção moveleira. Com isso, os móveis desenhados pela escola não ficavam só no papel, mas tinham um lugar para ser executados. Cabe aqui ressaltar que todo o mobiliário instalado na segunda sede foi desenvolvido por Ítalo Bianchi e sua equipe, inclusive a cadeira IADÊ, que se tornou um símbolo da escola.

O IADÊ foi concebido como um espaço de formação de profissionais que viessem a estabelecer novos conceitos, direcionados ao universo da "arquitetura de interiores". Essa nomenclatura, "arquitetura", questionada pelos arquitetos formados pelas instituições superiores, era uma forma de diferenciar a palavra "decoração", desgastada por ser utilizada por pessoas sem o devido preparo técnico. Para o IADÊ, no conceito de "arquitetura de interiores" estariam todos os projetos de criação de ambientes definidos pela arquitetura como espaços de vivência e convivência humana, onde os móveis e os objetos, baseados em estudos criteriosos, estabeleceriam as interfaces entre a arquitetura e o homem.

O projeto de arquitetura de interiores para o IADÊ, desde sua implantação em 1959, considerava o desenvolvimento de produtos (móveis e objetos), o ambiente e a identidade visual como um projeto sistêmico integrado, utilizando conceitos de racionalização e os princípios da ergonomia.

Em sua estrutura curricular, podemos observar as disciplinas de história da arte, introdução à arquitetura e estudos dos estilos existentes, não como princípios a ser copiados, mas para uma ampliação do repertório e uma visão cultural dos vários movimentos artísticos e arquitetônicos.

Aqui vamos transcrever o texto do folheto, editado em 1968, que define os objetivos do Curso de Decoração: 
- Objetivamos: Localização no tempo e no espaço dos fenômenos estilísticos, que fornecem os fatores críticos para a compreensão de nossa época.

- Aulas teóricas - projeções e análises de obras - que cultivam a capacidade de julgamento estético e estimulam as faculdades criadoras.

- Aulas práticas - que proporcionam as habilidades próprias do métier e possibilitam experiências de criação.

- Aulas técnicas - que oferecem os elementos concretos da realização profissional.

Considerando o caráter pioneiro e vanguardista da Bauhaus, que definiu novos paradigmas no ensino da arte, do design e da arquitetura, é possível afirmar que o IADÊ, sob a orientação de Ítalo Bianchi e dentro dos limites da nossa cultura, buscou basear-se, de forma intuitiva, nessa escola alemã tão admirada por seu idealizador, o que se revela, entre outras coisas, pelo formato de aulas teóricas, práticas e técnicas. Outra forte influência da Bauhaus foi que o IADÊ procurou estabelecer uma integração entre a instituição de ensino, a indústria e o mercado. Um exemplo disso foi o projeto de decoração da sede da Fundação Getúlio Vargas, em São Paulo, inaugurada em 1966.

\section{Pré-requisitos para ingressar no Curso de Decoração e nos cursos independentes}

\section{- Curso de Decoração}

Matrícula: Diploma do ginasial ou equivalente; não são admitidos alunos ouvintes.

Documentos:

$1^{\circ}$ ano: diploma, documento de identidade, atestado médico e três fotografias $3 \times 4$;

$2^{\circ}$ e $3^{\circ}$ anos: duas fotografias $3 \times 4$.

\section{- Cursos independentes}

Matrícula: Alunos regulares: diploma, documento de identidade, atestado médico e três fotografias $3 \times 4$.

Alunos ouvintes: documento de identidade e duas fotografias $3 \times 4$.

Ainda havia a seguinte informação: "Os documentos necessários para a matrícula não serão devolvidos, devendo ter firma reconhecida ou serem autenticados (fotocópias)". 


\title{
Objetivos, conceitos e diretrizes do Curso de Decoração
}

Os dados a seguir foram extraídos do folheto do IADÊ de 1965, portanto quando a instituição já completava seis anos de existência, e informava aos candidatos sua filosofia e estrutura curricular:

\begin{abstract}
Nós, o IADÊ, crescemos navegando contra a corrente. Temos, preservamos uma estrutura dinâmica. Correspondemos a uma mentalidade, não a uma fórmula. Nossas perspectivas não são pretensiosas: São ambiciosas, buscamos horizontes que estão sempre mais adiante. Sabemos que se pode mais, pode-se melhor: ambição de humildade. Em janeiro de 1965 vamos nos mudar para uma nova sede. Instalações ampliadas, melhores condições de trabalho, mais colaboradores: soma de experiências. Gostamos de ser IADÊ. Gostamos de ação, da disciplina, amamos igualmente o estro e a lógica. Alimentamos o entusiasmo, respeitamos a sabedoria. Acreditamos na harmonia dos contrastes. O IADÊ é jovem e pretende se manter jovem pela renovação, pela estrutura dinâmica. Gostamos de ensinar e de aprender. Estamos sempre começando de novo. Queremos ter a agilidade, o vigor, o perfil nítido, as escamas limpas dos peixes que navegam rio acima. Muitas centenas de alunos já nos acompanharam, outras centenas seguem conosco. Gostamos, eles e nós, de ser IADÊ.
\end{abstract}

São Paulo, novembro de $1964^{3}$

Interessante observarmos a forma pela qual o texto descreve de forma ágil e abrangente o perfil da escola e deixa transparecer a personalidade de seu idealizador, Ítalo Bianchi. Dificilmente encontraríamos, naquele período, instituições escolares com um discurso vigoroso e até de um certo ufanismo, exatamente no início de um período complexo na política nacional, com o governo militar no poder. Observamos também que esse texto demonstra a capacidade de criação de Ítalo Bianchi como a de um comunicador no âmbito da publicidade - e que ele se efetiva posteriormente como empreendedor no Nordeste brasileiro, quando implanta sua agência de publicidade no Recife e se transforma numa referência no setor.

Após a introdução do folheto, onde são definidas as qualidades da instituição e é caracterizado o momento de crescimento e mudança, vamos observar que o texto estabelece uma reflexão sobre o que seria o Curso de Decoração ou a forma pela qual a instituição pretendia explicar ao candidato os fundamentos da formação do decorador ou, mais especificamente, do arquiteto de interiores. 


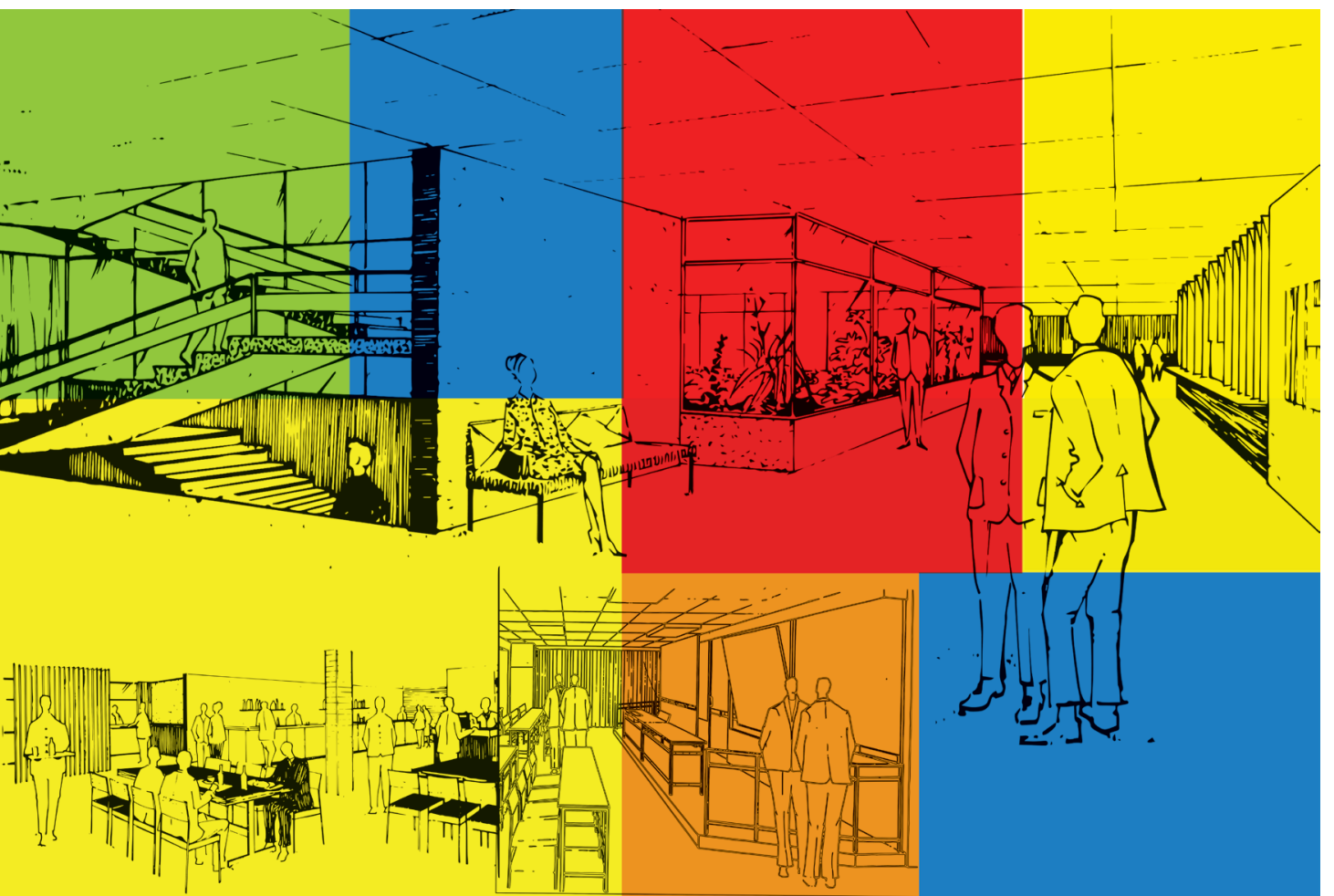

Fig 5. Ilustrações do projeto de interiores da FGV Fundação Getúlio Vargas. Fonte: Acervo de Maria Isabel de Souza Franco

Um mal-entendido se estabeleceu na interpretação do termo decoração, contrapondo duas concepções: a tradicional (fantasia-ornamento) e a contemporânea (organicidade-função). Tradicionalmente decorar era enfeitar, enriquecer. Para isto eram chamadas pessoas de bom gosto ou eruditos em estilos. Ainda se recorria a profissionais como decoradores-tapeceiros, decoradores-marceneiros. Neste esquema decorar era só luxo, soma de elementos acessórios e supérfluos em nome de uma discutível beleza. Hoje, definida uma cultura do século XX, torna-se anacrônica esta atividade de caráter superficial e muitas vezes amadorístico. Como resposta à consciência de exigências novas, a decoração atinge outra dimensão: torna-se arquitetura de interiores. Organização do espaço interno, procurando dar continuidade ao caráter da arquitetura atual. Demarcada como uma especialização técnica-estética, graças à sua independência, ganha profundidade e capacidade para resolver a parcela de necessidades humanas que lhe corresponde: integração do homem em seu ambiente. A decoração contemporânea pretende mais que harmonia formal, procura formas próprias para uma condição de vida harmônica. Base cultural, educação estética, formação técnica, cunho profissional fundamentam o programa do curso de decoração do IADÊ. 
Observamos aqui a preocupação do Instituto no sentido de fornecer aos estudantes conceitos de uma proposta que defina parâmetros técnicos e culturais na formação deles, que estabeleça um novo paradigma projetual, atento ao século 20. Acreditamos que os conceitos foram de extrema importância para a área, o que resultou na formação de excelentes profissionais. No entanto, devido ao corporativismo dos cursos superiores de arquitetura naquele período, o IADÊ não conseguiu aprovar sua proposta no Ministério da Educação e Cultura. Afora a Escola de Belas Artes do Rio de Janeiro, que mantinha um Curso de Artes Decorativas, a primeira faculdade implantar um Curso de Design de Interiores em São Paulo foi o Centro Belas Artes de São Paulo, na década de 1980. Dando continuidade ao folheto, após os esclarecimentos iniciais, vamos agora aos objetivos do curso.

\section{- Objetivamos:}

Localização no tempo e no espaço dos fenômenos estilísticos, que fornecem os fatores críticos para a compreensão da nossa época.

- Aulas teóricas - projeções e análise de obras - que cultivam a capacidade de julgamento estético e estimulam as faculdades criadoras.

- Aulas práticas - que proporcionam as habilidades próprias do métier e possibilitam as experiências de criação.

- Aulas técnicas - que oferecem os elementos concretos da realização profissional.

O estúdio anexo, atuante, ministra ao curso dados reais e polêmicos da atualização. Aqui, mais uma vez podemos supor que certos princípios e diretrizes têm como raízes a Bauhaus, da qual o idealizador do curso era um fiel seguidor.

No Curso de Decoração com duração de três anos, a estrutura curricular era composta da seguinte forma:

- $1^{0}$ ano - Decoração, Desenho e História da Arte;

- $2^{o}$ ano - Decoração, Desenho, História da Arte e Introdução à Arquitetura;

- 3o ano - Decoração e Complementos Culturais.

O Curso de Decoração de dois anos restringia-se à formação acadêmica básica. Posteriormente, ele passou a ter a duração de três anos, possibilitando o aprofundamento e a preparação maior no âmbito profissional. 


\title{
Estrutura curricular do Curso de Decoração e seus programas
}

\author{
Decoração I
}

\section{Composição:}

- Teoria: generalidades, espaço compositivo, esquemas, propriedades, proporção, módulos, valor gráfico e tonal, dominantes, valores psicológicos.

- Prática: exercícios de composição plana.

o curso estabelecia um formato sistematizado de ensino, possibilitando assim a formação de um profissional com forte embasamento teórico aplicado à prática e aos fundamentos da sintaxe visual.

Cor:

- Teoria: aspectos físicos, absorção e reflexos, luz e sombra, círculo fundamental, propriedades, harmonização, esquemas, valores psicológicos, a cor na decoração.

- Prática: exercícios de harmonização em abstrato e sua aplicação.

A conceituação da cor pressupõe o entendimento do fenômeno da luz e suas consequentes aplicações no âmbito da decoração.

\section{Materiais:}

- Teoria: generalidades, propriedades físicas, estéticas e funcionais, classificação e apresentação, tratamentos e acabamentos, madeiras, metais, cerâmicas, vidros, pedras, tecidos, couros e sintéticos.

- Prática: reconhecimento dos materiais.

Desde os primeiros anos já existia a preocupação da aproximação com as atribuições do futuro profissional.

\section{Decoração II}

Princípios de decoração:

- Teoria: conceituação contemporânea, espaço arquitetônico, organicidade e função, prerrogativas e medidas funcionais, mobiliário, iluminação, relação, fatores técnicos, tecnológicos, estéticos e funcionais, formação de ambientes, técnica de planejamento

- Prática: exercícios de composição no espaço, projetos de elementos arquitetônicos, peças de mobiliário, acessórios, distribuição de ambientes. 


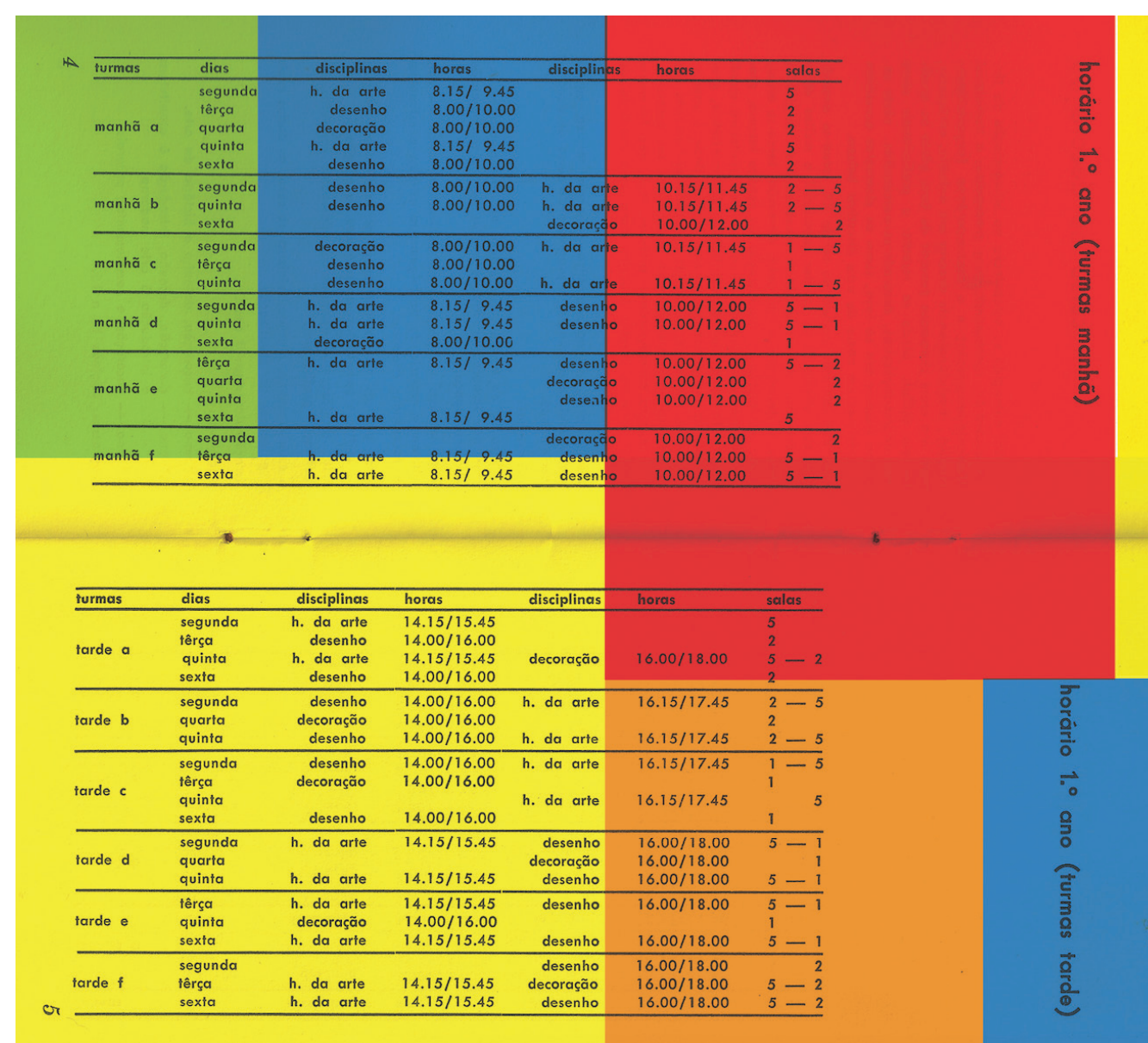

Fig 6. Impresso do Curso de Decoração IADÊ

Fonte Acervo de Maria Isabel de Souza Franco

Neste percurso, notamos que o Curso de Decoração pressupunha um profissional que estabelecesse uma forte interface com os conceitos de forma e função entre o ambiente e o mobiliário aliado ao espaço como unidade compositiva.

\section{Decoração III}

Orientação teórico-prática:

- Teoria: Expressão gráfica, croquis, esquema de cores, guache e colagem, artesanato e indústria: tapetes e tapeçaria, vidros e cristais, cerâmicas e porcelanas, ligações e encaixes, ferragens, mesas, portas e gavetas, cadeiras, camas, sofás-camas, estantes, armários, estofados, copas- cozinhas, banheiros, revestimentos, pisos, distribuição e circulação, móveis versáteis, 
móveis em série, decoração publicitária, personalidade e relações humanas, aspectos econômicos e sociais, trabalho de equipe e ética profissional.

- Trabalhos: exercícios de composição no espaço, projetos de elementos arquitetônicos, peças de mobiliário, acessórios, distribuição de ambientes.

Podemos observar a proximidade da metodologia empregada no Curso de Decoração com a formatação dos cursos superiores de arquitetura e desenho industrial daquele período.

Desenho I:

- Desenho à mão livre: domínio do traço, proporção, geometria plana: elemento geométricos, ângulos, circunferências, polígonos, concordância.

- Geometria do espaço: determinação do plano, relações entre plano e reta, relações entre planos, poliedros (prismas, cubo e pirâmide), superfícies e sólidos de revolução, curvas cônicas (elipse, parábola e hipérbole), geometria descritiva, noções fundamentais: projeção ortogonal (do ponto, da reta, de figuras planas e sólidos), iniciação ao desenho técnico.

- Perspectiva, Escalas: Representação de peças simples do mobiliário.

Desenho II:

- Perspectiva frontal, projeção ortogonal e perspectiva de curvas, perspectiva de planos inclinados e escadas, projeção ortogonal e perspectiva de móveis com modelo real, perspectivas de ambientes, convenções arquitetônicas, representação em corte de móveis, detalhes.

- Perspectiva intuitiva, proporção, grafismo, técnica do guache.

As sequências de desenho mesclavam a expressão gráfica individual com o rigor e o conhecimento da geometria, da precisão técnica da representação aplicada aos processos de produção em pequena, média e grande escala industrial. 
História da Arte

Informação histórica, indagação dos fenômenos culturais determinantes, análise crítica, exposição dos processos técnicos (projeção e comparação sistemática de obras) dos seguintes períodos: pré-história (pintura da região franco-cantábrica e do levante espanhol - monumentos neolíticos), Egito (arquitetura, pintura e escultura dos três impérios e da baixa época), Mesopotâmia e Pérsia Aquemênida (arquitetura e escultura), Grécia (de Creta ao Helenismo: arquitetura, escultura e cerâmica, povos itálicos, manifestações pré-históricas, Arte Etrusca), Roma (arquitetura, escultura e pintura da república e do império), Arte Bizantina (arquitetura, mosaico, ícones e iluminuras), Arte Islâmica (arquitetura), Arte Celta Irlandesa (joias e iluminuras), Arte Carolíngia e Românica (Escola Comacina - arquitetura e escultura), Arte Gótica (arquitetura, escultura, vitrais e iluminuras), Introdução ao Renascimento e ao Barroco (pintura, escultura e arquitetura).

\section{Introdução à Arte Moderna}

Aspectos conceituais e polêmicos: o problema da função da Arte, a pintura revolucionária e a tradição acadêmica, os valores pictóricos, aspectos de forma e conteúdo, crítica de Arte e História. Abordagem histórico-crítica: revolução francesa (neoclassicismo), romantismo, realismo, Escola de Barbizon, naturalismo, impressionismo, neoimpressionismo, simbolismo, os Nabis, fauvismo, primitivos e primitivismo, expressionismo, cubismo, futurismo, abstração, pintura metafísica italiana, dadaísmo, surrealismo, tendências contemporâneas. Localização, dados biográficos e análise de obras: Goya, Turner, Ingres, Delacroix, Millet, Courbet, Corot, Manet, Monet, Degas, Renoir, Cézanne, Gauguin, Van Gogh, Lautrec, Matisse, Rousseau, Nolde, Rouault, Picasso, Braque, Juan Griz, Léger, Delaunay, Lothe, Duchamp, Modigliani, Utrillo, Kandinsky, Klee, Mondrian, De Chirico, Dalí, Miró, Chagall, pintores da geração contemporânea.

\section{Introdução à Arquitetura}

Iniciação à compreensão da forma arquitetônica (Arquitetura na acepção ampla do termo: do edifício ao utensílio) por meio da abordagem histórica e da análise fenomenológica. Estudo da evolução das formas do ponto de vista cultural, estrutural, sensível e utilitário.

Divisão das formas, evolução das formas naturais, introdução às formas artificiais, noções de Antropologia, pré-história, Egito, Mesopotâmia, Grécia, Roma, Bizâncio, Romântico, Gótico, Renascimento, Barroco, Conceito de Estilo, Evolução do mobiliário - Luís XIII, Luís XIV, Luís XV e Luís XVI, Revolução Francesa, Estilos Ingleses, Barroco Português, Mobiliário brasileiro, Introdução ao movimento moderno, Revolução Industrial, 
Romantismo, Processo de Criação, Materiais de Construção, Função, Arts and Crafts, Art Nouveau, Mackintosch, Freysinet, Perret e Gaudí, Loos, Behrens e Muthesius, Richardson e Sullivan, Wright (organicidade), Mies van der Rhoe (estrutura-função), Le Corbusier (forma), Gropius e a Bauhaus (equipe, método e desenho).

Pela formação cultural e intelectual de Ítalo Bianchi, podemos compreender sua preocupação com o embasamento histórico ao nos depararmos com o volume de temas anteriormente expostos. Vale aqui destacar que o acervo de livros sobre os temas desenvolvidos e o acervo de slides eram incomparáveis em relação a outras instituições, quando os recursos visuais ainda eram algo inovador em nosso país. Quando nos defrontamos com a estrutura curricular, constatamos uma carga horária semanal de 4 horas/aula tanto no primeiro como no segundo ano, em que a ênfase era a Introdução à Arquitetura. A fundamentação teórica passava a ser um instrumento indispensável na concepção e no desenvolvimento dos projetos de arquitetura de interiores.

\section{Complementos culturais}

Palestras de professores do IADÊ e professores convidados sobre os temas: urbanismo, arquitetura, desenho industrial, artes gráficas, sociologia, estética, crítica de arte, cinema, teatro, cenografia, música, literatura, poesia, assuntos de atualidade. A preocupação do instituto em extrapolar o modelo da tradicional academia fez com que surgissem os eventos extraclasse, e a intelectualidade daquela época fosse chamada a contribuir trazendo informações sobre o que ocorria na metrópole e, por que não no mundo, já que ainda não havia os meios hoje conhecidos de comunicação. Essas atividades ocorriam em forma de palestras isoladas ou como complemento das disciplinas do curso.

\section{Professores integrantes, por ordem alfabética, do quadro oficial do Curso de Decoração}

Adriano Colangelo, Alvaro Landerset Simões, Elza Mauro, Emilio Fernandez Cano, Ítalo Bianchi, Julia Salomão, Marcio Colaferro, Mary Eliane Duarte Gold, Maria Albertina P. Alves, Maria Inêz Machado, Maria Isabel de Souza Franco, Maria Ligya Uchôa Cavalcanti, Maria Luiza Brandalise, Maria L. Gioia de Carvalho, Margarida de Azevedo, Marisa Moraes, Miriam Ayrosa, Neide Margonari, Nelson Achcar, Nelson Cukierkorn, Oswaldo Pongetti, Paulo Ramos Machado, Renata Beretta. 


\section{Personalidades que atuaram nos Cursos Livres}

Anatol Rosenfeld na disciplina de Estética e Teatro, Carlos Henrique Heck ministrando aulas sobre História da Arte, Carolina Andrade Bianchi em Introdução à Arte Moderna e Jean-Claude Bernardet na disciplina de Cinema.

\section{Estúdio Profissional IADÊ}

Em sua primeira sede, o Curso de Decoração, graças à visão profissionalizante de seu mentor Ítalo Bianchi, ganhou uma extensão para além de seus dois anos de duração, que recebeu o nome de Estúdio Profissional IADÊ. O grande contingente de profissionais que ali atuou era de ex- alunos do Curso de Decoração. Entre eles, Suemi Okano, Margarida Azevedo, Márcia Cunha, Elory Belluzzo Corrêa e Silva, Eneida Belluzzo, Emilio Fernandez Cano, Maria Isabel de Souza Franco, entre outros. Contou também com profissionais da área, como Idéo Bava, pioneiro do setor.

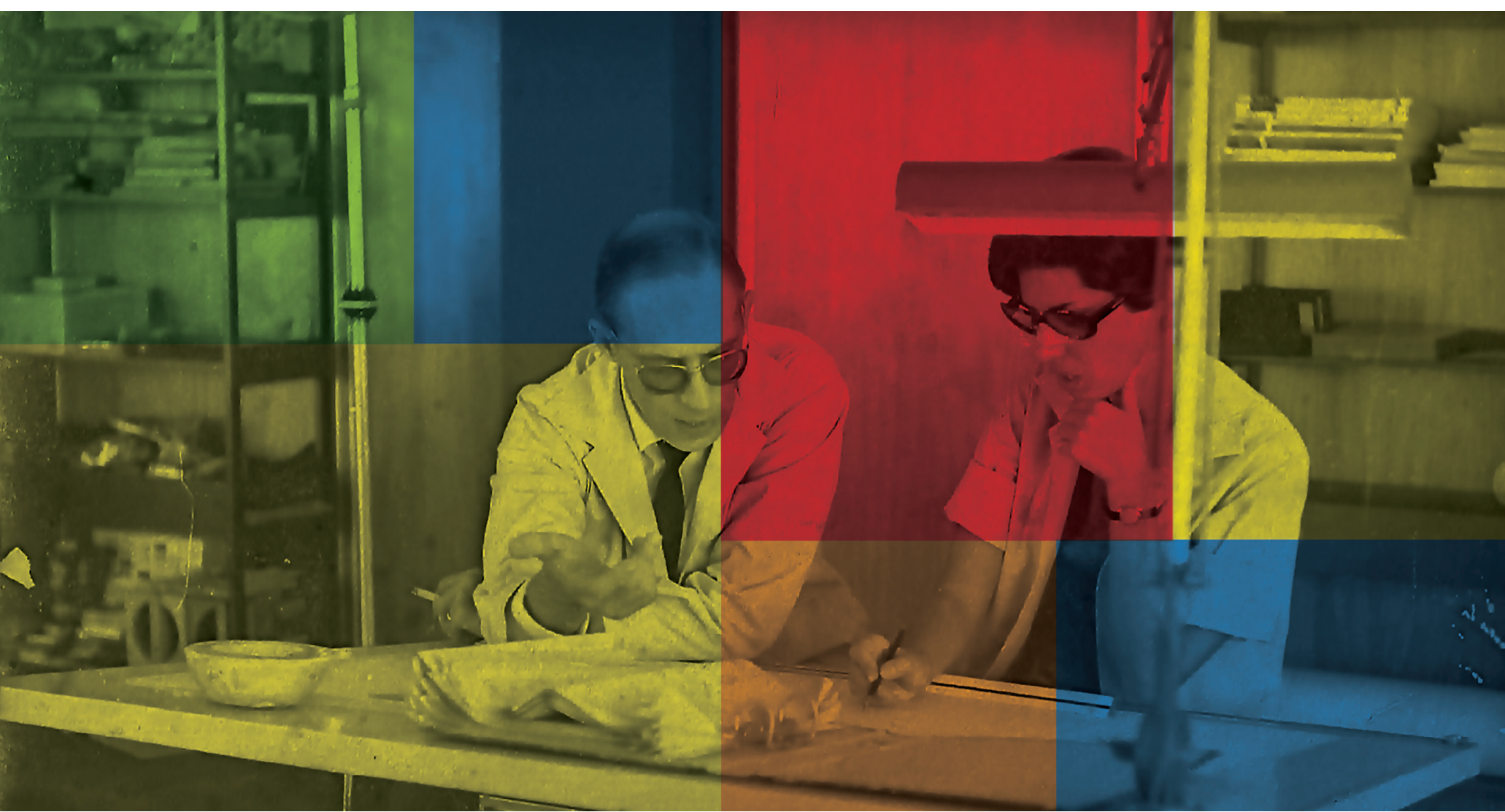

Fig 7. Estúdio IADÊ Emílio Fernandez Cano e Maria Isabel de Souza Franco

Fonte: Acervo de Maria Isabel de Souza Franco 
O conceito criado pelo IADÊ influenciou inúmeras outras escolas a criar suas empresas juniores, hoje uma prática em várias instituições acadêmicas. A criação do Estúdio Profissional foi uma inovação conceitual da escola, pois ele estabelecia a integração entre instituição, indústria e mercado, além do seu formato de atendimento ao cliente, que abrangia a concepção, a execução e o acompanhamento de projetos de interiores, espaços expositivos, promocionais, mobiliário e embalagens, caso da Atkinson (que por sinal era já um dos clientes de Ítalo Bianchi). Cumpre aqui destacar que o perfil dos clientes era bastante diferenciado e compreendia personalidades como Rosa Millan (proprietária do edifício onde o IADÊ teve sua sede, na Av. Paulista), Rachid Millan e empresas de pequeno e grande porte.

Na sede da Rua Martinho Prado, 191, foi desenvolvido seu mais importante projeto: o espaço interior da sede da Fundação Getúlio Vargas, na Av. Nove de Julho, inaugurado no primeiro semestre de 1966.

Consta no catálogo, em sua apresentação, o texto do diretor da FGV:

\footnotetext{
As páginas que se seguem darão a V.Sa. uma ideia sobre a nova e decisiva etapa do desenvolvimento da Escola de Administração de Empresas de São Paulo, da Fundação Getúlio Vargas: trata-se das suas novas instalações que estarão disponíveis para ocupação, a partir do primeiro semestre de $1966^{4}$.
}

O Estúdio Profissional do IADÊ trabalhou durante todo o ano de 1965 no projeto. Fizeram parte da equipe, liderada por Ítalo Bianchi, Maria Isabel de Souza Franco e Emilio Fernandez Cano, entre outros. Para aquele período, os conceitos ali implantados apresentavam um diferencial que determinava sua modernidade e contemporaneidade em relação à arquitetura institucional de interiores. Vale ressaltar que o projeto envolveu também a definição de todo o mobiliário, que pretendia atender, da melhor maneira possível, alunos, professores e colaboradores. As técnicas de representação gráfica eram artesanais, utilizando lápis, papel e nanquim. 


\section{Reflexões em torno do Curso de Decoração do ex-aluno, professor e coordenador Marcio Colaferro}

O texto a seguir refere-se à entrevista concedida à Leonora Fink por Marcio Colaferro, no dia 8 de abril de 2005, em seu ateliê no bairro do Sumaré, em São Paulo.

Podemos considerar, pelas afirmações desse profissional que ele faz uma reflexão questionadora em relação aos caminhos e descaminhos do IADÊ, em sua trajetória educacional.

Marcio Colaferro ingressou no IADÊ em 1966, como funcionário, onde fazia fotos e slides de obras de arte para as aulas de História da Arte. Simultaneamente estudava piano e cursava engenharia, e, no constante impasse de optar por uma profissão, desistiu da engenharia e concentrou-se no estudo de piano, o que não era admitido pela família. Através da amizade com um primo de Maria Isabel de Souza Franco, conheceu o IADÊ, onde foi atuar profissionalmente e se entusiasmou com a formação no âmbito das artes visuais, pois até aquela data, 1965, não tivera a oportunidade de trabalhar nesse segmento. Conseguiu uma bolsa de estudos no Curso de Decoração, e pressentiu que seu lado artístico não era a música, mas sim o universo visual.

Para ele, o Colégio Técnico de Comunicação IADÊ teve um grande azar, porque quando se transformou em curso médio profissionalizante era uma novidade, mas logo em seguida outros cursos em todo o país também se transformaram em profissionalizantes. Marcio acompanhou todas as etapas de mudança da escola, tanto físicas quanto conceituais. No entanto, considera que o IADÊ "verdadeiro" sempre foi o do Curso de Decoração, sem similar naquele período, e poderia ser avaliado como o melhor na formação de profissionais de decoração de interiores. No seu entender, o erro foi o IADÊ não ter se transformado no curso de desenho industrial, como ocorreu naquele período dos anos 1960, em que o Rio de Janeiro implantou a ESDI Escola Superior de Desenho Industrial.

Ao discorrer sobre as personalidades do mundo criativo em São Paulo, enfatiza a presença corpo docente do IADÊ dos seguintes profissionais: Álvaro de Moya; Antonio Benetazzo, um professor excepcional ("Eu vi ele ser assassinado na frente do IADÊ pela ditadura. A polícia passou com o carro em cima, deu tiro... e todos viram!"); Carlos Fajardo, artista plástico; Carlos Henrique Heck; Cássia Maria Machado e Christa Brigitte Lukas, designers; Eneida Regina Belluzzo; Elory Belluzzo Correa e Silva; Fuad Jorge Cury; o arquiteto Geraldo Vespaziano Puntoni, professor da FAU-USP; Haron Cohen; Maria Isabel Franco de Souza; Jacob Aron Corch; Jorge de Souza Carvajal; José da Costa Chaves; Laonte Klawa; Luís Torres; Marcelo Nitsche; Maria Augusta Tambellini; Maristela Jardim Gáudio; Mary Eliane Duart Gold; Odiléa Helena Setti Toscano, uma teórica do design, já falecida; Raymundo de Paschoal, também já falecido; Ricardo Ohtake, que foi secretário da Cultura e hoje dirige o Instituto Tomie Ohtake; Ruy Ohtake, arquiteto de projeção internacional; Ro- 
berto Lombardi; Sami Bussab; Samuel Szpiegel; Sandra Corrêa da Silva; Semi Amar; Sérgio Ferro, entre outros, que na maioria eram muito jovens, ainda desconhecidos, mas que foram a base da cultura nascente da arquitetura e do desenho industrial naquele período.

Prosseguindo no seu depoimento, Marcio Colaferro demonstra acreditar que o Curso de Decoração, que efetivamente deu os primeiros passos para a concepção do "desenho industrial" - que para ele sempre foi "design" -, possibilitou sua formação, assim como das designers Cássia Klawa e Adriana Adam, que lá estudaram no período em que o curso tinha a duração de três anos. Marcio Colaferro deixou a coordenação no período da implantação do Curso Colegial, quando o antigo Curso de Decoração foi reduzido para um ano de duração, pois considerava um erro o que a direção, do professor Emilio, de Maria Isabel e de Michiro Motoda, estava definindo como conteúdo programático juntamente com os arquitetos que assumiram como professores. Para ele, a denominação desenho industrial nunca foi pertinente, e repetia constantemente que ele desenvolvia "design", que pode ser arte, ou "design artístico". A redução da carga horária do Curso de Decoração para um ano foi definida pelo professor José da Costa Chaves. Isso, no entender de Marcio Colaferro, resultou em uma redução do conteúdo, bem como da conceituação da atividade profissional. Quando José da Costa Chaves se demitiu da escola, Colaferro assumiu a coordenação do Curso de Decoração, no início dos anos 1970, e assim conseguiu redimensionar para dois anos sua duração. No entanto, ele percebeu que o ambiente estava conturbado e não tinha mais o "clima" das propostas cultivadas por Ítalo Bianchi, alicerçadas nos conceitos da Bauhaus. Assim, apesar de lhe terem oferecido participação na sociedade, ele não aceitou, devido a suas atividades profissionais no âmbito da arquitetura de interiores e na loja de produtos para decoração que havia criado. Para o IADÊ, no entender de Colaferro, faltavam as oficinas práticas, que na visão de Ítalo Bianchi deveriam ser implantadas. As visitas à marcenaria Pentágono, ligada ao IADÊ, eram uma forma de aproximação do estudante com a realidade produtiva, mas ainda preponderava o caráter teórico. Apesar disso, ainda assim era melhor haver essa aproximação do que nenhuma.

Como ex-aluno, professor e coordenador apaixonado pela escola que lhe deu o embasamento profissional, Marcio Colaferro faz críticas aos cursos existentes em São Paulo. $O$ fruto dessa procura incessante por novos caminhos resultou na formação de um contingente de profissionais atuantes até os nossos dias e que se recordam com frequência de uma instituição que provocava, questionava e apontava possíveis caminhos para a modernidade, seja pelo seu conteúdo, seja pela sua forma de se apresentar. 0 Curso de Decoração e seu Estúdio Profissional alcançaram sua plenitude, mas tiveram uma vida curta, de aproximadamente oito anos. Não podemos nos esquecer da fase inicial deles, em que se buscavam suas diretrizes e, quem sabe, da etapa final, onde predomina a melancolia pelo que "tinha sido" o IADÊ. 
No seu entender, o Curso Colegial deixou uma grande contribuição para a formação de técnicos de comunicação, no entanto, ficou faltando para o IADÊ dar o passo maior e implantar a faculdade de design de objeto, da decoração e gráfica.

Ao final, vamos observar um certo tom de desabafo, de amargura e também de alegria pelo dever cumprido nas palavras de Marcio Colaferro:

\footnotetext{
Uma pena que não tivemos a oportunidade de implantar os cursos de nível superior. Mas quando eles (professores Emilio Fernandez Cano e Maria Isabel) quiseram que eu assumisse a coordenação do curso, tive muito trabalho durante o período de cinco ou seis anos, pois administrava uma equipe de quarenta professores. Eram realizados treinamentos no mês de janeiro, durante todos os dias, para definir as estratégias e o planejamento do curso. Apesar da complexidade de reunir professores, no final os projetos integrados ainda eram corrigidos nos quinze dias do mês de julho sem ganho extra, e recebíamos, sim, o salário de férias... assim o tempo passou e comecei a ficar cansado... ${ }^{5}$
}

O que observamos é um misto de inquietude, de procura de novos caminhos, de busca por alternativas culturais advindas dos modelos europeus que estabeleciam os novos paradigmas da sociedade do século 20. A proposta do IADÊ, capitaneada pela visão prospectiva de Ítalo Bianchi, foi marca e, ao mesmo tempo, proposta de mudança, calcada ainda no modelo aristocrático de entender os ambientes domésticos e comerciais.

Quanto ao Colégio Técnico de Comunicação, ele precisa ser estudado dentro de novos paradigmas. Os tempos já eram outros, a faixa etária compreendia a adolescência, vivíamos então uma mixagem do ensino de segundo grau com a formação técnica, que, como sabemos até os nossos dias, é um tema repleto de paradoxos. O perfil do Curso de Decoração definia um profissional abrangente, mas que tinha parâmetros determinados, enquanto o Curso Técnico de Comunicação era passível de ambiguidades, pois mesclava a possível necessidade de um profissional para escritórios e departamentos que estavam se instalando em nossa capital com as expectativas dos jovens e de suas famílias, que almejavam o ingresso nas universidades em seus cursos de arquitetura, desenho industrial, publicidade, jornalismo, entre outros.

Permanece o questionamento: caso o IADÊ tivesse, naquele período, o aval do Ministério da Educação e Cultura para abrir seus cursos de nível superior - pois, como observamos pela sua estrutura curricular e sua filosofia de trabalho, apresentava todos os requisitos para isso -, poderia ter sido o curso pioneiro de desenho industrial em São Paulo, pois conceito e material humano não lhe faltavam. 
1 Material impresso do acervo particular de Maria Isabel de Souza Franco. 2 Depoimento concedido por Maria Isabel de Souza Franco ao autor, no dia 17 de novembro de 2017, em encontro que durou aproximadamente duas horas no bairro de Pinheiros, em SP.

3 Texto extraído do folheto promocional do curso de decoração do IADÊ, de autoria de ítalo Bianchi. Fonte: acervo do autor, novembro de 1964.

4 Texto extraído do portfólio do Estúdio Profissional do IADÊ. Fonte: Acervo do autor, 1966.

5 Texto extraído do portfólio do Estúdio Profissional do IADÊ. Fonte: Acervo do autor, 1966.

\section{Referências}

ALBERTI, Verena. Manual da História Oral. Rio de Janeiro: FGV, 2005.

BARDI, Pietro Maria. Excursão ao território do design. São Paulo: Banco Sudameris S.A., 1986. BARROS, José D'Assunção. Sobre a feitura da micro história. Revista OPSIS Vol.7, no. 9, p.167-181, 2007.

BONSIEPE, Gui. Design, Cultura e Sociedade. São Paulo: Blücher, 2011.

CARDOSO, Rafael (org.) O design brasileiro antes do design. São Paulo: Cosac Naif, 2005. CARDOSO, Rafael. Uma introdução à História do Design. São Paulo: Editora Blücher, 2008. CARVAlHo, Ana Paula Coelho de. o Ensino Paulistano de Design: a formação das escolas pioneiras. São Paulo 2012. Dissertação de Mestrado (Design e Arquitetura), Faculdade de Arquitetura e Urbanismo da Universidade de São Paulo, São Paulo, 2012.

Catálogo Concreta 56 a raiz da forma. Museu de Arte Moderna. São Paulo, SP, 2006.

COUTO, Rita M. S. Escritos sobre o ensino de design no Brasil. Rio de Janeiro: Rio Books, 2008. DROSTE, Magdalena. Bauhaus 1919-1933. Bauhaus-Archiv Museum für Gestaltung. Colônia: Taschen, 2010.

HABER, Nadine. A década de 70: apogeu e crise da ditadura militar brasileira. São Paulo: Ática, 1992.

LEON, Ethel. Design Brasileiro: quem fez, quem faz. São Paulo: Editora SENAC, 2005.

LEON, Ethel. IAC Primeira Escola de Design do Brasil. São Paulo: Editora Blücher, 2014.

MIRANDA, Jétehro Cardoso de. Entrevista concedida ao Jornal do Decorador - Informativo da Associação Brasileira de Decoradores. Número 1 março/abril 1983.

MOTOYAN, Shozo. Educação Técnica e Tecnológica em Questão. São Paulo: Editora UNESP, 1995. NIEMEYER, Lucy. Design no Brasil: origens e instalação. Rio de Janeiro: Editora 2AB, 2000.

ORTEGA Y GASSET, José. A rebelião das Massas. Lisboa: Editora Relógio D’ Água, 2008. RODRIGUES, Antônio Jacinto. A Bauhaus e o ensino artístico. Lisboa: Editorial Presença, 1989. RONNENBERG, Ami. o livro dos símbolos. Reflexões sobre imagens arquetípicas. Colônia: Taschen, 2012.

SEGRETO, Leonora Fink. Projeto IADÊ Resgate. 2005. TCC do Curso de Especialização em Design Multimídia Latu Sensu Faculdades SENAC de Comunicação, Artes e Design. São Paulo, 2005.

SOUZA, Pedro Luiz Pereira. Notas para uma história do design. $4^{\mathrm{a}}$ edição. Rio de Janeiro: Editora $2 \mathrm{AB}, 2008$.

Recebido: 17 de abril de 2020 . WICK, Rainer. Pedagogia da Bauhaus. São Paulo: Martins Fontes, 1989.

Aprovado: 05 de maio de 2020. 